\title{
Role and its utilization of beneficial micro-organisms for sustainable crop production
}

\author{
S.K. CHOUDHARY*, S.K. GUPTA, M.K. SINGH AND S. SHERAZ MAHDI \\ Department of Agronomy, BAC, Bihar Agricultural University, Sabour, BHAGALPUR (BIHAR) INDIA \\ (Email : saurabhkkv2885@gmail.com)
}

\begin{abstract}
Soil micro-organisms are important component of integrated nutrient management and soil biodiversity system. They play a pivotal role in the functioning of plants by influencing their physiology and development. It is very important role in biogeo-chemical cycles and has been used for crop production for decades. Plant-bacterial interactions in the rhizosphere are the determinants of plant health and soil fertility. Soil bacteria which are beneficial to plant growth, referred to plant growth promoting rhizobacteria (PGPR), which are capable of promoting plant growth by colonizing the plant root. Symbiotic nitrogen-fixing bacteria include the Cyanobacteria of the genera Rhizobium, Brady rhizobium, Azorhizobium, Allorhizobium, Sinorhizobium and Mesorhizobium. Plant growth promotion and development can be facilitated both directly and indirectly. Indirect plant growth promotionincludes the prevention of the deleterious effects of phytopathogenic organisms. This can be achieved by the production of siderophores, i.e. small metal-binding molecules. Biological control of soil-borne plant pathogens and the synthesis of antibiotics have also been reported in several bacterial species. Another mechanism by which PGPR can inhibit phytopathogens is the production of hydrogencyanide (HCN) and/or fungal cell wall degrading enzymes, e.g., chitinase and $\beta$-1,3-glucanase. Direct plant growth promotion includes symbiotic and non-symbiotic PGPR which function through production of plant hormones suchas auxins, cytokinins, gibberellins, ethylene and abscisic acid. Production of indole-3-ethanol or indole-3-acetic acid(IAA), PGPR also help in solubilisation of mineral phosphates and other nutrients, enhance resistance to stress, stabilize soil aggregates, and improve soil structure and organic matter content. PGPR retain more soil organic N, and other nutrients in the plant-soil system, thus, reducing the need for fertilizer.
\end{abstract}

Key Words : PGPR Symbiotic, Non-symbiotic, P and K solubilisation, Phytohormones, Bio control

View Point Article : Choudhary, S.K., Gupta, S.K., Singh, M.K. and Mahdi, S. Sheraz (2016). Role and its utilization of beneficial microorganisms forsustainable crop production. Internat. J. agric. Sci., 12 (2) : 370-378, DOI:10.15740/HAS/IJAS/12.2/370-378.

Article History : Received : 20.03.2016; Accepted : 27.05.2016

* Author for correspondence 